\title{
Exergaming for children with probable developmental coordination disorder (p-DCD)/DCD 給患有 (潛在) 發展性協調障礙兒童的虚擬遊戲
}

\author{
Wai Wing Ada MA Joanne Hoi Ling WONG \\ Department of Health and Physical Education, \\ The Education University of Hong Kong, Hong Kong, CHINA
}

\begin{abstract}
The purpose of this study was to examine the effectiveness of exergaming for improving balance, eye-hand coordination (EHC), and exercise enjoyment among children with special educational needs (SEN) and probable developmental coordination disorder (p-DCD). This study adopted a single-group intervention with paired results. Nine primary school students (seven boys and two girls, aged 7-10 years) were recruited and underwent a 3-month exergaming intervention involving three 30-minute sessions per week. Xbox One Kinect was used under the supervision of the researchers and physical education (PE) teachers. Pre- and post-intervention scores were calculated for data analysis. Motor performance was assessed using the Movement Assessment Battery for Children - Second Edition Test. The participants' gaming experiences were captured using Fun Toolkit. The Wilcoxon signed-rank test showed significant improvements in balance and EHC, but no significant differences in enjoyment scores. The findings indicated a positive impact of exergaming on primary school students with SEN and motor problems. The outcomes indicate that exergaming is an effective strategy for improving motor skills in children with SEN and p-DCD/DCD. Therefore, exergaming could be incorporated into PE curricula to motivate students to participate in physical activities in order to improve their physical health and well-being.
\end{abstract}

\section{摘 要}

本研究探討虛擬遊戲對改善有特殊教育需要 (SEN) 和（潛在）發育協調障礙的兒童的平衡、眼手協調和享受運動的功效。 九名小學生參加為期三個月, 每週三次30分鐘的訓練。訓練前後的遊戲分數、運動表現和遊戲體驗都被分析。研究結果顯示平衡 力和眼手協調顯著地改善, 但享受度沒有明顯差異。這説明虛擬遊戲對有SEN和動作協調問題的小學生有積極影響, 改善運動技 能。因此, 將這納入體育課程, 可鼓勵學生參加體能活動, 改善身心健康。

\section{Introduction}

Exercise has been well documented as a strategy to improve health. However, students with special educational needs (SEN), particularly those with developmental coordination disorder (DCD), are considered as victims of low physical fitness (Sahagian-Whalen, Missiuna, \& Rivard, 2010). DCD is a chronic disorder in children with motor impairment (Department of Health [DH], 2007) that prevents them from learning and executing motor skills (Cacola, 2016). In clinical settings, the Movement Assessment Battery for Children - Second
Edition Test (MABC-2) is commonly used to assess motor performance of children aged 3-16 years (Schoemaker, Niemeijer, Flapper, \& Smits-Engelsman, 2012; Wuang, Su, \& $\mathrm{Su}, 2012$ ). Scoring 6-7 is identified as probable DCD (p-DCD) and below the 5th percentile is considered to suffer from severe motor deficiencies (i.e., DCD; Jelsma, Geuze, Mombarg, \& Smits-Engelsman, 2014).

Compared with children with typical development (TD), the motor skills and weight status of children with DCD explained $7.6 \%$ and $5.0 \%$ of the variance in participation diversity, respectively, and $29.6 \%$ of the children with 
DCD were overweight or obese (Fong et al., 2011), illustrating that they had a relatively high likelihood to suffer from obesity due to a lower degree of physical activity (Puhl \& Latner, 2007). In addition, they did not enjoy exercise as much as those without DCD (Cairney et al., 2007).

In Hong Kong, 5-6\% of primary school students suffered from eye-hand coordination (EHC) problems, with 1240 students suffering from p-DCD and 506 with DCD in 2007-2009 (Hong Kong Sanatorium and Hospital, 2014). Among those with p-DCD/DCD, 52.6\%, $14.4 \%$, and $14.4 \%$ had problems with fine motor coordination, gross motor coordination, and both types, respectively (Lee, 2011). Exergaming has been shown to improve balance and visual motor skills (Sheehan \& Katz, 2012, 2013; Staiano \& Calvert, 2011), and thus potentially a method to enhance enjoyment and performance in physical activity for the patients.

\section{Exergaming}

Exergaming incorporates exercises that require $\mathrm{EHC}$ and whole-body movement. This form of gaming was first introduced in the 1980s and was modified in the late 1990s in the form of Dance Dance Revolution (DDR; Behrenshausen, 2007). An increasing number of studies on exergaming has supported its positive effects on physical and cognitive health (e.g. Best, 2013; Hilton et al., 2015; Staiano \& Calvert, 2011). These studies have shown that exergames not only enhance physical activity among upper elementary school children (Pope, Lewis, \& Gao, 2015) but also facilitate psychomotor learning and motor skill development among students with SEN (Cai \& Kornspan, 2012). The skills obtained from gaming can be transferred to daily activities, thereby improve health (Eckert, Gomez-Martinho, Meneses, \& Martinez, 2017; Hilton et al., 2015). Exergames also cultivate social interaction among players by providing a platform to form friendships (Park, Yoo, Sungwon, Park, \& Song, 2012). Specifically, Chamberlin and Gallagher (2008) found that third- and fourth-grade students showed greater leadership, social skills, self-esteem, and academic success after exergames.

\section{Exergaming and Balance}

Balance refers to the ability to maintain stability and postural control to prevent falls (Pollock, Durward, \& Rowe, 2000). Fall-related injuries can result in physical dysfunction, motor disability, loss of independence, and a decline in daily activity, particularly among elderly people and children with DCD (Mombarg, Jelsma, \& Hartman, 2013; Van Diest, Lamoth, Stegenga, Verkerke, \& Postema, 2013).

In Hong Kong, fall-related injuries are common; about $20 \%$ of community-dwelling adults aged $\geq 65$ experience falls every year and approximately $75 \%$ of them suffer from injuries, e.g. head trauma and bone fractures (Centre for Health Protection, 2013). Fall is also the most common accident among children (DH, 2010) and could lead to serious consequences related to childhood physical development, e.g. intracranial injuries and skull fractures (Burrows et al., 2015).

Exergaming is widely accepted to train balancing (Harris, Rantalainen, Muthalib, Johnson, \& Teo, 2015; Kramer, Dettmers, \& Gruber, 2014). Particularly, seven people aged 84-85 years with balance deficiencies were recruited for a three-month Wii Fit-based intervention. The results showed that their balancing and walking speeds improved significantly throughout the study (Agmon, Perry, Phelan, Demiris, \& Huong, 2011).

Poor postural control is another risk factor for falling. Specifically, nine healthy older adults showed significant improvements in trunk acceleration patterns after exergaming (Lamoth, Caljouw, \& Postema, 2011). A similar protocol was adopted to fourth-grade students and their postural control was also improved in six weeks (Sheehan \& Katz, 2013).

Children with DCD exhibit motor developmental delay so are at high risk of falling. Exergaming is viable to improve their balance skills (Di Tore, 2016; Jelsma et al., 2014). Seventeen children with p-DCD improved balance after a five-week intervention as evaluated by standing on the dominant leg and walking in a straight line (Smits-Engelsman, Jelsma, Ferguson, \& Geuze, 2015). 


\section{Exergaming and EHC}

EHC is a fundamental skill that involves hands and eyes working together to perform a task. Strong EHC and fine motor development are essential for childhood development and physical performance (Education and Manpower Bureau [EMB], 2007; National Childcare Accreditation Council, 2008). EHC deficiencies may appear during childhood development and can be ameliorated through practice (EMB, 2007). Sensory and motor system improvements are crucial to enhance EHC and can be effectively enhanced if specific training is provided (Ricotti, 2011).

The application of gaming technology in relation to EHC development has been investigated for decades. Griffith, Voloschin, Gibb, and Bailey (1983) indicated that gamers had better EHC than did nongamers. A further investigation was conducted using dance-based games to elevate the participants' general coordination level (Di Tore \& Raiola, 2012). Staiano and Calvert (2011) revealed that exergaming facilitated the development of fine motor skills and EHC. Ma and Qu (2016) also established the effectiveness of exergaming for EHC development among primary school students. Investigations have also been conducted for special populations. Exergaming aids children with DCD to practice and improve motor skills for the real life (Campos \& Fernandez, 2016; George, Rohr, \& Byrne, 2016) and promotes physical fitness (Caro, Tentori, Martinez-Garcia, \& Zavala-Ibarra, 2017; Vernadakis, Papastergiou, Zetou, \& Antoniou, 2015). A pilot study conducted on 12 children with autism spectrum disorder revealed that the children significantly reduced repetitive behaviors after playing DDR (Anderson-Hanley, Tureck, \& Achneiderman, 2011).

\section{Exergaming and Exercise Enjoyment}

Enjoyment is a crucial determinant of exercise motivation (Scanlan \& Simons, 1992). Arent, Landers, and Etnier (2000) revealed a positive relationship for exercise and mood in the elderly. Motivation is crucial in childhood learning processes in physical education (PE) classes (Hassandra, Goudas, \& Chroni, 2003; Kretschmann, 2014). Scanlan and Lewthwaite (1986) revealed a positive relationship between enjoyment and continual exercise participation, through which children's self-esteem was increased (Tremblay, Inman, \& Willms, 2000). Activityrelated excitement was shown to promote physical fitness among adolescents and recommended to integrate into PE curricula (Hashim, Grove, \& Whipp, 2008).

Exergames are fun to play and incorporate favorable elements of traditional video games and physical activities. Bailey and McInnis (2011) found that 39 children enjoyed an exergaming intervention and observed minor sexual differences. They also showed that more overweight children enjoyed the activity than lean children. Exergaming is intrinsically motivating because of inter-player interactions and challenges, explaining why interactive gaming is more preferable than more sedentary exercises (Best, 2013).

In short, despite the fact that children with p-DCD/ DCD have balance and EHC deficiencies and unable to develop the skills as TD, very few studies have addressed the effects of interactive exergaming on motor skills (balance and EHC), and exercise enjoyment among students with SEN, particularly those with p-DCD in Hong Kong. Therefore, this paper fills the literature gap by highlighting its effectiveness among local primary school students with SEN and p-DCD/DCD of improve their physical performance and fitness. The findings can serve as a reference in promoting physical exercise participation among such students.

\section{Methodology}

\section{Study design and settings}

This study involved a single-group intervention design with paired results. No control group was included.

\section{Participants}

Researchers' connections with school teachers was implemented in participant recruitment, i.e. convenience sampling. Ethical approval was obtained from the Human Research Ethics Committee of The Education University of Hong Kong. Written informed consent was obtained from the children's parents or guardians. In this study, children with SEN aged 7-10 years with a typical intelligence quotient (IQ) of 90-109 (Psych Support Assessment Services, 2016) and motor deficiencies were recruited from a primary school. Those with medical histories including health problems, e.g. cardiovascular disease, epilepsy, and postoperative interventions were 
excluded. Firstly, school teachers selected children with SEN with inferior motor skills $(\mathrm{n}=15)$ based on school records. These children were then further assessed motor skill deficiencies using the MABC-2. Children who scored below the 16th percentile (i.e. standard score of $\leq 7$ ) of the total score were included; six participants scored 6-7 (p-DCD) and three scored $\leq 5$ (DCD).

\section{Intervention}

The participants were invited to a pre-intervention educational seminar which focused on the importance of physical exercise and fitness, exergaming, and EHC. Elite athletes were invited as ambassadors to demonstrate and increase participants' exercise motivation. Xbox One Kinect with motion sensors was used as a training tool (Vernadakis et al., 2015). The intervention consisted of three 30-minute exergame sessions a week for three months under the supervision of PE teachers and the researchers. The participants played in pairs and the training venue was divided into eight game zones (Fig. 1). Three exergames options were introduced: Shape Up, Kinect Sport Rival, and Just Dance 2016, all of which provided unlimited exercise opportunities, visual feedback, and motivational reinforcement and they were switched after each 12-day cycle (i.e., one month) (Table 1). All participants played identical amounts of time and difficulty levels for controlling the training effect.

\section{Outcome Measurement}

The independent variables were demographic data, e.g. gender, age, and body mass index (BMI), whereas the dependent variables included balance, EHC, and enjoyment scores. All measurements were conducted pre- and postintervention, and data on students' satisfaction toward exergaming were collected in the first and final weeks of the intervention.

\section{MABC-2}

The MABC-2 was used to assess children's balance and EHC. The test consists of eight tasks in three categories, namely Manual Dexterity (MD; three items), Aiming and Catching (AC; two items), and Balance (Bal; three items). The test and the subscales had goodto-excellent internal consistency (Cronbach $\alpha$ : overall $=0.90, \mathrm{MD}=0.81, \mathrm{AC}=0.84, \mathrm{Bal}=0.88 ;$ Wuang et al., 2012). The test is commonly used to assess children in three age bands: 3-6, 7-10, and 11-16 years (Camden, Rivard, \& Missiuna, 2013). The tasks for age 7-10 were employed in this study. Raw scores were used to calculate total standard (range: 1-19; mean = 10; standard deviation $(\mathrm{SD})=3$ ) and percentile scores. A standard score of $>7$ was classified as average motor performance, whereas score of $6-7$ or below the 5th percentile indicated a risk of or had serious motor deficiency, respectively (Jelsma et al., 2014). Measurements were conducted under the supervision of a licensed physiotherapist.

\section{Fun Toolkit Version 3}

The Fun Toolkit (Version 3) was used to collect students' enjoyment about their experiences with computer games (Read, 2008). Two elements of the toolkit, the Smileyometer and Again-Again Table, were adopted in this study and previously exhibited a strong correlation (Spearman rho $=0.780, \mathrm{p}<0.0005)$ among 24 children aged 8-9 (Read, 2008). The Smileyometer is a visual analogue 5-point Likert scale with face expressions (Awful $=1$ point, Brilliant = 5 points; Fig. 2). Participants were asked to choose one of the five faces after each game. The Again-Again Table was used to check which activity the child wished to play again. Pictures of the activities were shown and the children ticked "yes" (2 points), "maybe" (1 point), or "no" (0 point) for each game, having considered the questions, "Would you like to play it again?" (Fig. 3; Read, 2008). The scores were summed to illustrate the type(s) of exergames that the children generally preferred and the degree of exercise enjoyment.

\section{Data Analysis}

Data was analyzed using SPSS (version 21, SPSS Inc., Chicago, IL, USA). The Wilcoxon signed-rank test was used to compare the pre- and post-intervention scores for the effects of exergaming on balance, EHC, and students' enjoyment in playing exergames. The significance level was set at $\mathrm{p}=0.05$. 


\section{Results}

\section{Baseline Characteristics}

All participants completed the MABC-2 and exercise enjoyment tests. During the three-month intervention, the participants played exergames 36 times. Their attendance ranged from $80-100 \%$. At the time of admission, the mean age was 8.33 and the SD was 0.866. Baseline characteristics were summarized in Table 2.

\section{Effects of Exergaming}

The effect of training was summarized in Table 3. A significant improvement in the MABC-2 standard scores and each subscale after intervention. The effect size for the $\mathrm{MD}, \mathrm{AC}$, and $\mathrm{Bal}$ subscales were 0.52 , 0.63 , and 0.63 , respectively. No significant difference was found in exercise enjoyment after the intervention $(p=0.317)$.

\section{Discussion}

This study mainly examined whether an exergaming intervention had a positive influence on balance (indicated by $\mathrm{Bal}$ ), EHC (indicated by $\mathrm{MD}$ and $\mathrm{AC}$ ) and exercise enjoyment among children with p-DCD/DCD. Firstly, nine children who were trained using Xbox One Kinect for three months showed significant improvements in balance, as illustrated in the mean standard MABC-2 scores (Table 3), which echoes the findings of Jelsma et al. (2014), thereby supporting that exergaming has a positive impact on balance development among primary school students with p-DCD. Secondly, our results revealed a significant improvement in EHC among children with p-DCD/ DCD after the exergaming intervention, according to the MABC-2 subscales of MD and AC (Table 3). To the best of our knowledge, this is the first study to evident that exergaming effectively facilitates EHC development in children with $\mathrm{p}-\mathrm{DCD} / \mathrm{DCD}$. Taken together, the present study demonstrated that exergaming can potentially improve and refine motor skills and movement patterns among children with $\mathrm{p}-\mathrm{DCD} / \mathrm{DCD}$; thereby help them to produce coordinated movements. Continual motor training is believed to elevate their competence and confidence when participating in physical activities, and thus improve their health. Thirdly, we evaluated whether the participants enjoyed the exergames. This was crucial because most children refused to participate in activities that they found difficult and lost interest over long periods (Allender,
Cowburn, \& Foster, 2006), especially those with learning difficulties or disabilities (Durkin, Boyle, Hunter, \& Conti-Ramsden, 2013; Shields \& Synnot, 2016). Our data illustrated that all participants in the present study enjoyed the games throughout the intervention period, echoing the findings of Brazendale et al. (2015), Jelsma et al. (2014) and Smits-Engelsman et al. (2015), and a significant heightening was not found. This could be attributed to the pre-intervention seminar, which included exergaming introduction and competitive game demonstrations performed by elite athletes and student representatives. Participants' responses to the seminar were overwhelmingly positive, and thus their initial motivation to the exergames was high, which might lead to the non-statically-significant difference in exercise enjoyment. Notably, students' high level of enjoyment was sustained throughout the intervention period, in accordance with Jelsma et al. (2014); thereby indicating that motivating young individuals to engage in physical exercise is essential (Biddiss \& Irwin, 2010; Brazendale et al., 2015; Cairney et al., 2012).

The disadvantages of children with SEN may negatively affect their gaming experiences and choices (Durkin et al., 2013). However, our findings revealed that they could compete with others, either by playing against a nonhuman virtual character or their peers. This provided the students with a social experience and motivation to adhere to the intervention. This agreed with Di Tore (2016), Kooiman and Sheeman (2015) and Smits-Engelsman et al. (2015), who have illustrated that multiplayer gaming provided social interactions among players and yielded high levels of enjoyment and motivation (Osorio, Moffat, \& Sykes, 2012; Pang \& Crouse, 2013). This may also explain why the participants' high level of interest was sustained over a long time in the present study.

Few studies have examined the effects of exergaming on balance, EHC, and exercise enjoyment in children with $\mathrm{p}-\mathrm{DCD} / \mathrm{DCD}$. The present paper fills the literature gap in this field. Consequently, the findings could be transferred to educational settings, prompting its incorporation into PE curricula to motivate children with $\mathrm{p}-\mathrm{DCD} / \mathrm{DCD}$ to engage in more active lifestyles. We recommended that future PE curricula may refer the protocol of the present study, which seems to be easily arranged without considerably disrupting the daily routine. 
This study had two limitations in the present study. Firstly, the sample size was limited $(\mathrm{n}=9)$. Therefore, a type II error may occur. Secondly, the study did not involve any control group; thus, the outcomes may have been influenced by factors other than the exergaming intervention.

\section{Conclusion}

The findings of this study illustrated the positive impact of exergaming on balance and $\mathrm{EHC}$, indicating the effectiveness in improving motor performance in children with p-DCD/DCD. Exercise enjoyment, which is crucial to motivate and enhance self-efficacy, can also be sustained. Since this is the first study to explore the effects of exergaming on balance, EHC, and exercise enjoyment in children with p-DCD/DCD, empirical research in this field should further examine the methods to enhance confidence and competence among them.

\section{Disclosure}

The authors declare no conflict of interest.

\section{Author Contributions}

W.W.A.M contributed to the conception and design of this study. J.H.L.W performed the statistical analysis and drafted the manuscript. W.W.A.M critically reviewed the manuscript and supervised the whole study process. All authors read and approved the final manuscript.

\section{References}

Agmon, M., Perry, C. K., Phelan, E., Demiris, G., \& Huong, Q. N. (2011). A pilot study of Wii Fit exergames to improve balance in older adults. Journal of Geriatric Physical Therapy, 34, 161-167.

Allender, S., Cowburn, G., \& Foster, C. (2006). Understanding participation in sport and physical activity among children and adults: A review of qualitative studies. Health Education Research, 21, 826-835.

Anderson-Hanley, C., Tureck, K., \& Achneiderman, R. L. (2011). Autism and exergaming: Effects on repetitive behaviors and cognition. Psychology Research and Behavior Management, 4, 129-137.
Arent, S. M., Landers, D. M., \& Etnier, J. L. (2000). The effects of exercise on mood in older adults: A meta-analytic review. Journal of Aging and Physical Activity, 8, 407-430.

Bailey, B. W., \& McInnis, K. (2011). Energy cost of exergaming: A comparison of the energy cost of 6 forms of exergaming. Archives of Pediatrics and Adolescent Medicine, 165, 597-602.

Behrenshausen, B. G. (2007). Toward a (kin)aesthetic of video games for youth: A systematic view. Games and Culture, 2, 335-354.

Best, J. R. (2013). Exergaming in youth, effects on physical and cognitive health. Zeitschrift fur Psychologie, 221, 72-78.

Biddiss, E., \& Irwin, J. (2010). Active video games to promote physical activity in children and youth. Archives of Pediatrics and Adolescent Medicine, 164, 664-672.

Brazendale, K., Graves, B. S., Penhollow, T., Whitehurst, M., Pittinger, E., \& Randel, A. B. (2015) Children's enjoyment and perceived competence in physical education and physical activity participation outside of school. Emotional \& Behavioral Disorders in Youth, 1, 65-69.

Burrows, P., Trefan, L., Houston, R., Hughes, J., Pearson, G., Edwards, R. J., ... Kemp, A. M. (2015). Head injury from falls in children younger than 6 years of age. Archives of Disease in Childhood, 100, 1032-1037.

Cacola, P. (2016). Physical and mental health of children with developmental coordination disorder. Frontiers in Public Health, 4, 1-6.

Cai, S. X., \& Kornspan, A. S. (2012). The use of exergaming with developmentally disabled students. Strategies, 25, 15-18.

Cairney, J., Hay, J., Mandigo, J., Wade, T., Faught, B. E., \& Flouris, A. (2007). Developmental coordination disorder and reported enjoyment of physical education in children, European Physical Education Review, 13, 81-98. 
Cairney, J., Kwan, M. Y. W., Velduizen, S., Hay, J., Bray, S. R., \& Faught, B. E. (2012). Gender, perceived competence and the enjoyment of physical education in children: A longitudinal examination. International Journal of Behavioral Nutrition and Physical Activity, 9, $1-8$.

Camden, C., Rivard, L. M., \& Missiuna, C. (2013) Canchild Centre for Childhood Disability Research in Facilitating a DCD diagnosis: Movement Assessment Battery for Children (MABC-2). Retrieved from: http://elearning.canchild.ca/dcd_pt_workshop/ assets/identification/mabc-2.pdf

Campos, C. M., \& Fernandez, D. C. H. (2016). The benefits of active video games for educational and physical activity approaches: A systematic review. Journal of New Approaches in Educational Research, 5, 115-122.

Caro, K., Tentori, M., Martinez-Garcia, A. I., \& ZavalaIbarra, I. (2017). FroggyBobby: An exergame to support children with motor problems practicing motor coordination exercises during therapeutic interventions. Computers in Human Behavior, 71, 479-498.

Centre for Health Protection. (2013). Non-Communicable Disease Watch: Falls in the Elderly. Retrieved from: http://www.chp.gov.hk/files/pdf/ncd_watch_ nov2013.pdf

Chamberlin, B., \& Gallagher, R. (2008, May). Exergames: Using video games to promote physical activity. Paper presented at Children, Youth, and Families at Risk Conference, San Antonio, TX.

Department of Health. (2007). Childhood Developmental Disorders. Retrieved from: http://www.dhcas.gov. hk/english/health_pro/files/SeriesII_DCD_Eng. pdf

Department of Health. (2010). Injury Survey 2008. Retrieved from: http://www.chp.gov.hk/files/pdf/ injury_survey_eng.pdf

Di Tore, P. A., \& Raiola, G. (2012). Exergames and motor skills learning: a brief summary. International Research Journal of Applied and Basic Sciences, 3, $1161-1164$.
Di Tore, P. A. (2016). Exergames, motor skills and special educational needs. Sport Science, 9, 67-70.

Durkin, K., Boyle, J., Hunter, S., \& Conti-Ramsden, G. (2013). Video games for children and adolescents with special educational needs. Zeitschrift für Psychologie, $221,79-89$

Eckert, M., Gomez-Martinho, I., Meneses, J., \& Martinez, J. F. (2017). New approaches to exciting exergame-experiences for people with motor function impairments. Sensors, 17, 1-22.

Education and Manpower Bureau. (2007). An Introductory Guide to Fundamental Movement. Retrieved from: http://cd1.edb.hkedcity.net/cd/pe/TC/rr/FM_e.pdf

Fong, S. S. M., Lee, V. Y. L., Chan, N. N. C., Chan, R. S. H., Chak, W. K., \& Pang, M. Y. C. (2011). Motor ability and weight status are determinants of out-of-school activity participation for children with developmental coordination disorder. Research in Developmental Disabilities, 32, 2614-2623.

George, A. M., Rohr, L. E., \& Byrne, J. (2016). Impact of Nintendo Wii games on physical literacy in children: Motor skills, physical fitness, activity behaviors, and knowledge. Sports, 4, 1-10.

Griffith, J. L., Voloschin, P., Gibb, G. D., \& Bailey, J. R. (1983). Differences in eye-hand motor coordination of video-game users and non-users. Perceptual and Motor Skills, 57, 155-158.

Harris, D. M., Rantalainen, T., Muthalib, M., Johnson, L., \& Teo, W. P. (2015). Exergaming as a viable therapeutic tool to improve static and dynamic balance among older adults and people with idiopathic Parkinson's disease: A systematic review and meta-analysis. Frontiers in Aging Neuroscience, 7 , $1-12$.

Hashim, H. A., Grove, J. R., \& Whipp, P. (2008). Relationships between physical education enjoyment processes, physical activity, and exercise habit strength among Western Australian high school students. Asian Journal of Exercise and Sports Science, 5, 23-31. 
Hassandra, M., Goudas, M., \& Chroni, S. (2003). Examining factors associated with intrinsic motivation in physical education: A qualitative approach. Psychology of Sport and Exercise, 4, 211-223.

Hilton, C. L., Attal, A., Best, J. R., Reistetter, T. A., Trapani, P., \& Collins, D. M. (2015). Exergaming to improve physical and mental fitness in children and adolescents with autism spectrum disorders: Pilot study. International Journal of Sports and Exercise Medicine, 1, 1-6.

Hong Kong Sanatorium and Hospital. (2014). Găishàn értóng shǒuyăn zhīť̌ xiétiáo. Retrieved from: http:// www.hksh.com/sites/default/files/publications/zhhant/9550beccac42bfac9c0337be9938ba55.pdf

Jelsma, D., Geuze, R. H., Mombarg, R., \& SmitsEngelsman, B. C. M. (2014). The impact of Wii fit intervention on dynamic balance control in children with probable developmental coordination disorder and balance problems. Human Movement Science, $33,404-418$.

Kooiman, B. J., \& Sheeman, D. P. (2015). The efficacy of exergames for social relatedness in online physical education. Cogent Education, 2, 1-15.

Kramer, A., Dettmers, C., \& Gruber, M. (2014). Exergaming with additional postural demands improves balance and gait in patients with multiple sclerosis as much as conventional balance training and leads to high adherence to home-based balance training. Archives of Physical Medicine and Rehabilitation, 95, 1803-1809.

Kretschmann, R. (2014). Student motivation in physical education - The evidence in a nutshell. Acta Kinesiologica, 8, 27-32.

Lamoth, C. J. C., Caljouw, S. R., \& Postema, K. (2011). Active video gaming to improve balance in the elderly. Studies in Health Technology and Informatics, 167, 159-164.
Lee, M. Y. F. (2011). CAS epidemiological report on developmental coordination disorder from 2007 to 2009. Child Assessment Service Epidemiology and Research Bulletin, 8, 61-68.

Ma, W. W., \& Qu, L. (2016). The effect of exergaming on eye-hand coordination among primary school children: A pilot study. Advances in Physiology Education, 6, 99-102.

Mombarg, R., Jelsma, D., \& Hartman, E. (2013). Effect of Wii-intervention on balance of children with poor motor performance. Research in Developmental Disabilities, 34, 2996-3003.

National Childcare Accreditation Council. (2008). Supporting children's development. Putt. Child. First, $28,3-5$.

Osorio, G., Moffat, D. C., \& Sykes, J. (2012). Exergaming, exercise, and gaming: Sharing motivations. Games for Health Journal, 1, 205-210.

Pang, W., \& Crouse, J. (2013). Playing in parallel: The effects of multiplayer modes in active video game on motivation and physical exertion. Cyberpsychology, Behavior, and Social Networking, 16, 423-427.

Park, T. W., Yoo, C. K., Sungwon, P. C., Park, B., \& Song, J. (2012). Transforming solitary exercises into social exergames. Retrieved from: http://nclab. kaist.ac.kr/papers/Conference/park12cscw.pdf

Pollock, A. S., Durward, B. R., \& Rowe, P. J. (2000). What is balance? Clinical Rehabilitation, 14, 402406.

Pope, Z. C., Lewis, B. A., \& Gao, Z. (2015). Using the transtheoretical model to examine the effects of exergaming on physical activity among children. Journal of physical activity and health, 12, 12051212.

Psych Support Assessment Services. (2016). Wechsler Intelligence Scale for Children (WISC-V). Retrieved from: http://www.child-psychologist.com.au/ wechsler-intelligence-scale-for-children.html 
Puhl, R. M., \& Latner, J. D. (2007). Stigma, obesity, and the health of the nation's children. Psychological Bulletin, 133, 557-580.

Read, J. C. (2008). Validating the Fun Toolkit: An instrument for measuring children's opinions of technology. Cognition, Technology \& Work, 10, 119128.

Ricotti, L. (2011). Static and dynamic balance in young athletes. Journal of Human Sport and Exercise, 6, 616-628.

Sahagian-Whalen, S., Missiuna, C., \& Rivard, L. (2010). Developmental coordination disorder: What does it mean to me? Retrieved from: https://canchild.ca/ system/tenon/assets/attachments/000/000/207/ original/developmental_coordination_disorder_ adolescents.pdf

Scanlan, T. K., \& Lewthwaite, R. (1986). Social psychological aspects of competition for male youth sport participants: IV. Predictors of enjoyment. Journal of Sport Psychology, 8, 25-35.

Scanlan, T. K., \& Simons, J. P. (1992). The construct of sport enjoyment. In G. C. Roberts (Eds.), Motivation in Sport and Exercise (pp. 199-215). Champaign, IL: Human Kinetics.

Schoemaker, M. M., Niemeijer, A. S., Flapper, B. C. T., \& Smits-Engelsman, B. C. M. (2012). Validity and reliability of the Movement Assessment Battery for Children-2 Checklist for children with and without motor impairments. Developmental Medicine \& Child Neurology, 54, 368-375.

Sheehan, D. P., \& Katz, L. (2013). The effects of a daily, 6-week exergaming curriculum on balance in fourth grade children. Journal of Sport and Health Science, 2, 131-137.
Sheehan, D. P., \& Katz, L. (2012). The impact of a six week exergaming curriculum on balance with grade three school children using the Wii FIT+. International Journal of Computer Science in Sport, 11, 5-22.

Shields, N., \& Synnot, A. (2016). Perceived barriers and facilitators to participation in physical activity for children with disability: A qualitative study. $B M C$ Pediatrics, 16, 1-10.

Smits-Engelsman, B. C. M, Jelsma, L. D., Ferguson, G. D., \& Geuze, R. H. (2015). Motor learning: An analysis of 100 trials of a ski slalom game in children with and without developmental coordination disorder. PLOS ONE, 10, 1-19.

Staiano, A. E., \& Calvert, S. L. (2011) Exergames for physical education courses: Physical, social, and cognitive benefits. Child Development Perspectives, 5 , 93-98.

Tremblay, M. S., Inman, J. W., \& Willms, J. D. (2000). The relationship between physical activity, selfesteem, and academic achievement in 12-year-old children. Pediatric Exercise Science, 12, 312-323.

Van Diest, M., Lamoth, C. J., Stegenga, J., Verkerke, G. J., \& Postema, K. (2013). Exergaming for balance training of elderly: State of the art and future developments. Journal of NeuroEngineering and Rehabilitation, 10, 1-12.

Vernadakis, N., Papastergiou, M., Zetou, E., \& Antoniou, P. (2015). The impact of an exergame-based intervention on children's fundamental motor skills. Computers \& Education, 83, 90-102.

Wuang, Y. P., Su, J. H., \& Su, C. Y. (2012). Reliability and responsiveness of the Movement Assessment Battery for Children - Second Edition test in children with developmental coordination disorder. Developmental Medicine \& Child Neurology, 54, $160-165$. 
Table 1. Game rotation schedule.

\begin{tabular}{|l|l|}
\hline Period & Types of video game \\
\hline $1^{\text {st }}$ month $(9 \mathrm{Feb}-8 \mathrm{Mar})$ & Shape Up \\
$2^{\text {nd }}$ month $(10 \mathrm{Mar}-10 \mathrm{Apr})$ & Kinect Sport Rival \\
$3^{\text {rd }}$ month $(24 \mathrm{Apr}-24 \mathrm{May})$ & Just Dance 2016 \\
\hline
\end{tabular}

Table 2. Baseline characteristics $(\mathrm{n}=9)$.

\begin{tabular}{|l|l|l|}
\hline & Mean & Standard Deviation \\
\hline Age $(\mathrm{y})$ & 8.33 & 0.866 \\
BMI & 18.26 & 4.168 \\
MABC-2 test standard score & 5.56 & 1.014 \\
Exercise enjoyment & 6.89 & 0.333 \\
\hline
\end{tabular}

Table 3. Dependent variable statistics in the pre- and post-intervention $(n=9)$.

\begin{tabular}{|l|l|l|l|}
\hline & Mean difference & Z statistics & -value \\
\hline MABC-2 test standard score & 3.77 & -2.677 & $0.007 * *$ \\
Manual Dexterity & 3.11 & -2.214 & $0.027^{*}$ \\
Aiming and Catching & 4.67 & -2.677 & $0.007 * *$ \\
Balance & 2.12 & -2.687 & $0.007 * *$ \\
Enjoyment score & 0.11 & -1.000 & 0.317 \\
\hline
\end{tabular}

Wilcoxon-signed rank test; *p $<0.05 ; * * \mathrm{p}<0.01 ; * * * \mathrm{p}<0.001$

Figure 1. Game Settings.

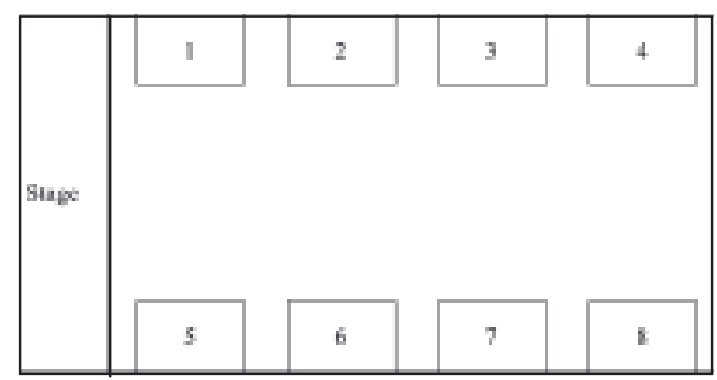

Figure 3. Again-Again Table.

Would you like to play it again?

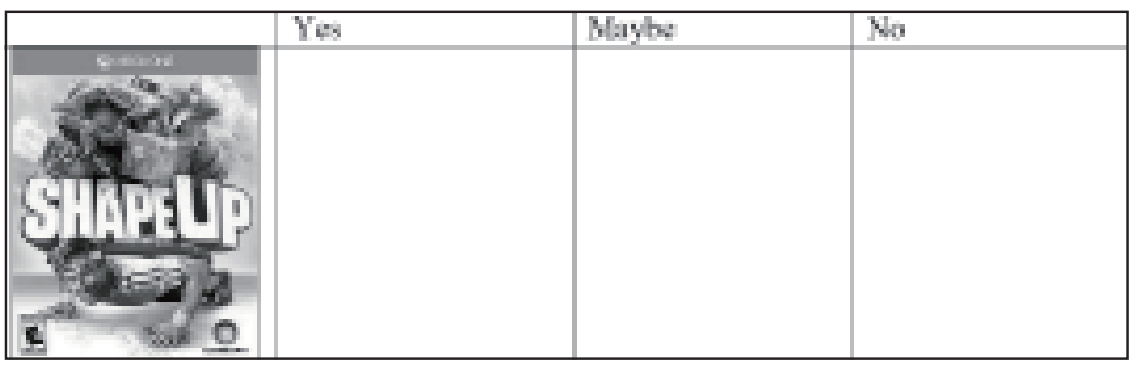

\section{Correspondence}

Ma Wai Wing Ada, $\mathrm{PhD}$

Department of Health and Physical Education, The Education University of Hong Kong,

10 Lo Ping Road, Tai Po, New Territories, Hong Kong, China.

Tel.: +(852) 29487672.

Email: ama@eduhk.hk
Figure 2. Smileyometer.

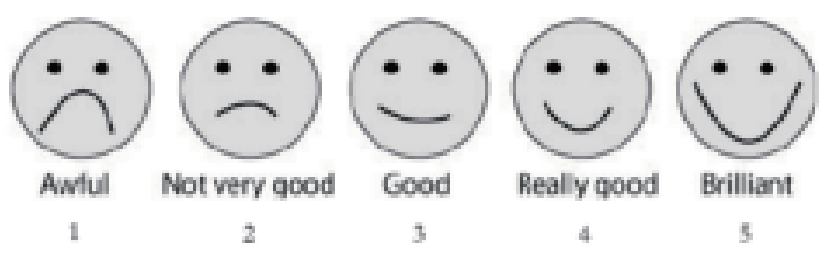

